\title{
Demografik Değişkenlerin Yaşam Doyumuna Etkisinin Lojistik Regresyon Analizi İle Belirlenmesi: Konaklama Sektörü Örneği
}

\begin{abstract}
DOI: 10.26466/opus.589382
*

Boran Toker* - M. Bahadır Kalıpç*

* Doç. Dr., Akdeniz Üniversitesi, Serik İşletme Fakültesi, Serik / Antalya / Türkiye

E-Posta: borantoker@akdeniz.edu.tr

ORCID: 0000-0002-4658-1934

** Öğr. Gör., Akdeniz Üniversitesi, Manavgat Meslek Yüksekokulu, Manavgat / Antalya / Türkiye E-Posta: bkalipci@gmail.com

ORCID: $0000-0001-7310-890 \mathrm{X}$

\section{Öz}

Bu çalışmanın amacl, yaş, cinsiyet, eğitim, çalışma durumu, sektörde çalışma senesi ve konaklama işletmesinde çalışma senesi gibi demografik değişkenlerin yaşam doyumu üzerindeki etkilerinin belirlenmesidir. Çalışmada anket tekniği kullanılmıştır. Veriler, Diener, Emmons, Larsen ve Griffin (1985) Yaşam Doyum Ölçeği ve kişisel bilgi formu kullanılarak elde edilmiştir. Uygulama, Antalya'nın önemli bir turizm destinasyonu olan Manavgat'taki konaklama işletmelerinde görev yapan 598 işgören üzerinde gerçekleştirilmiştir. Araştırma verileri SPSS 23.0 istatistik paket programı ile analiz edilmiştir. İstatistiksel anlamda öncelikle ölçeklerin güvenilirliği (Cronbach Alpha) test edilmiştir. Ardından yaşam doyumu ölçeğine faktör analizi (principal component analysis) uygulanmış ve tek boyut elde edilmiştir. Çalışmada, kategorik değişkenlerden oluşan bağımsız değiş̧kenlerin, iki düzeyi olan bağımlı değişkene etkilerini belirleyebilmek için lojistik regresyon analizi kullanılmıştır. Lojistik regresyon analizi sonucunda, işgörenlerin yaşam doyumların etkileyen demografik değişkenlerden tam zamanlı ya da sezonluk çalışma durumunun istatistiksel olarak anlamlı bir etkiye sahip olduğu saptanmış ve tam zamanlı çalışmanın sezonluk çalışmaya göre yaşam doyumunu azaltacağı ortaya koyulmuştur. Diğer demografik değişkenlerin etkilerinin ise istatistiksel olarak anlamlı olmadiğı tespit edilmiştir.
\end{abstract}

Anahtar Kelimeler: Yaşam doyumu; Demografik değiş̧kenler; Lojistik regresyon; Konaklama sektörü 


\title{
Determination of the Effects of Demographic Variables on Life Satisfaction by Logistics Regression Analysis: Case of the Accommodation Sector
}

*

\begin{abstract}
The aim of this study is to determine the effects of demographic variables such as age, gender, education, working status, working years in sector and working years in accommodation business on life satisfaction. Survey technique was used in the study. The data were obtained by using Diener et al. (1985) Life Satisfaction Scale and personal information form. The research was carried out on 598 employees working in the accommodation business in Manavgat, an important tourism destination of Antalya. Research data were analyzed with SPSS 23.0 statistical package program. Firstly, the reliability of the scales (Cronbach Alpha) was tested. Afterwards, factor analysis (principal component analysis) was applied to the life satisfaction scale and a single dimension was obtained. In this study, logistic regression analysis was used to determine the effects of independent variables consisting of categorical variables on the binary dependent variable. As a result of the logistic regression analysis, it was determined that the full-time or seasonal working status, which is one of the demographic variables affecting the life satisfaction of the employees, had a statistically significant effect and it was revealed that the full-time work would reduce life satisfaction according to the seasonal work. The effects of other demographic variables were not statistically significant.
\end{abstract}

Keywords: Life satisfaction; Demographic variables; Logistic regression; Accommodation sector 


\section{Giriş}

Hizmet sektöründe yer alan konaklama işletmelerinde yaşam doyumunun, performans ve verimliliği artırmada hem işgören hem de işletme açısindan önemli etkenlerden biri olduğu söylenebilir. Günümüzde, çağdaş yöneticilerin sadece hizmet kalitesi odaklı olmaması gerektiği; işgörenlerin yaşam doyumlarının artması ile işletmenin verimliliği ve işgörenlerin bağlılığının da artırılmasının mümkün olacağı artık önemsenmesi gereken bir gerçektir. Öznel iyi oluşun insanların yaşam kalitesindeki büyük önemi nedeniyle, araştırmacılar farklı kültürlerde öznel iyi oluşun farklı unsurlarını yordamak ve ilişkilerini saptamak için çeşitli araştırmalar yapmaktadırlar (Joshanloo ve Afshari, 2011, s.106). Öznel iyi oluşun bir bileşeni olarak yaşam doyumu, erişkinlik dönemi çalışmalarında en eski ve en çok araştırılan konulardan biri olmuştur (Lewis ve Borders, 1995, s.94). Yaşam doyumu, bir bireyin yaşamının genel kalitesini bütün olarak olumlu bir şekilde değerlendirme derecesidir. Başka bir deyişle, kişinin yaşadığı hayatı ne kadar sevdiğini ortaya koyar (Veenhoven, 1996, s.6). Özetle, yaşam doyumunu, bireyin kendi yaşamı hakkındaki genel değerlendirmelerini kapsayan bilişsel bir yargı şeklinde tanımlanmak mümkündür (Yetim, 1991, s.113-114). Aynı zamanda yaşam doyumu, bir bireyin özlemlerinin gerçek başarılarıyla karşılaştırılmasından kaynaklanan genel varoluş koşullarının bir değerlendirmesini ifade eder. Kişinin alg1ladığı yaşam doyumu, temel olarak bireyin yaşamında arzuladığı hedeflere doğru ilerlemesine ilişkin bilişsel değerlendirmelerini de yansıtır (Brown ve Duan, 2007, s.268).

Öte yandan, Donovan ve Halpern (2002, s.32) “insanların mutlu olduklarında, düşüncelerinde daha açı fikirli ve yaratıcı olma eğiliminde olduklarını; bunun aksine, mutsuz, stresli ya da tatminsiz olduklarında ise 'dar bakış açısı' ve sabit düşünce sergileme eğiliminde olduklarını' ifade etmişlerdir. Bununla birlikte, yaşamlarından memnun olan insanlar daha sağlıklı olma eğilimindedir ve yaşam doyumu işten ayrılma niyetiyle ters orantılıdır (Donovan ve Halpern, 2002, s.32; Lambert vd., 2009, s.690).

Bireysel olarak değerlendirilen yaşam doyumunun farklı demografik değişkenlerin etkisi ile nasıl bir değişim göstereceği çeşitli çalışmalarla ortaya koyulmuştur. Bu çalışmada konaklama işletmelerinde görev yapan işgörenlerin yaşam doyumlarının cinsiyet, yaş, eğitim düzeyi, işletmede 
çalışma süresi, sektörde çalışma süresi ve çalışma durumu gibi demografik değişkenlerle nasıl bir etkileşim içinde olduğunun tespiti amaçlanmıştır. Turizm işletmeleri üzerinde gerçekleştirilmiş bu tür bir çalışmaya rastlanmamış olmasından dolayı, literatüre katkı yapılması da hedeflenmiştir.

\section{Yaşam doyumu}

Yaşam doyumu kavramı, ilgili literatürde genellikle "öznel iyi oluş / öznel iyi olma hali" gibi temel yapıların altında bir bileşen olarak incelenmektedir. Bilişsel düzeyde, öznel iyi oluş, kişinin işi, evliliği ve diğer alanları ile ilgili belirli tatmin olma düzeylerinden beslenen genel tatmin duygusunu içerir. Yüksek seviyede öznel iyi oluş duygusuna sahip bireyler, olayları olumlu bakış açısı ile değerlendirmelerinden dolayı öncelikle tatminkâr duygular hissetmektedirler. Düşük seviyede öznel iyi oluş duygusuna sahip bireyler ise yaşam koşullarını ve olaylarını olumsuz olarak değerlendirirler ve bu nedenle kaygı, depresyon ve öfke gibi hoş olmayan duygular yaşarlar (Myers ve Diener, 1995, s.11). Medley (1976) yaşam doyumunu, yaşamla ilgili öznel bir mutluluk ve memnuniyet duygusu olarak tanımlamıştır (akt. Lee, Hwang, Kim ve Daly, 2004, s.633). Yaşam doyumu; yaşamı değiştirme isteği, mevcut yaşamdan memnun olma, geçmişten doyum, gelecekten doyum ve diğerlerinin birey hakkındaki görüşlerini kapsamaktadır. Doyum alanlarını ise iş, aile, boş zaman, sağlık, finans, kişilik ve kişinin yakın çevresi oluşturmaktadır (Diener, Suh, Lucas ve Smith, 1999, s.277).

Genel olarak yaşam doyumu bir bireyin tüm yaşamını ve bu yaşamın farklı boyutlarını da içerir (Toker ve Çelik, 2016, s.337). Bu çerçevede, yaşam doyumu bir bireyin yaşam deneyimlerinin hem fiziksel hem de psikolojik olarak kişisel istek ve ihtiyaçlarını karşılama derecesi olarak tanımlanmaktadır (Rice, 1984, s.3). Bu istek ve ihtiyaçlar, örneğin bireyler çal1şan, ebeveyn, eş veya arkadaş rolünü üstlendiğinde, yaşamın çeşitli alanlarında otaya çıkabilir (Demerouti, Bakker, Nachreiner ve Schaufeli, 2000, s.456).

Yaşam doyumu aynı zamanda bireyin kendi yaşamının kavramsal bir değerlendirmesini veya yargısını içerir. Bu kapsamda değerlendirildiğinde ise yaşam doyumu bir tutum olarak görülebilir. Yaşam doyumu, kişinin kendi yaşamının hoşlandığı veya hoşlanmadığ1 yönlerinin özet bir 
değerlendirmesidir (Saldamll, 2008, s.700). Bu çerçevede, yaşam doyumunun birçok olumlu faydaları da bulunmaktadır. Başlıca faydası, insanların genel refahlarını etkileyen, kendileri ve yaşamları hakkında iyi hissetmeleridir. Yaşamından memnun olan insanlar daha mutlu olma ve diğer insanlara da daha iyi davranma eğilimindedirler. Çalışma hayatındaki sorunları ve meseleleri verimli ve etkin bir şekilde ele almaları daha olasıdır (Pasupuleti, Allen, Lambert ve Cluse-Tolar, 2009, s.320). Yaşam doyumu, insanın yaşamındaki genel doyum derecesinin bilişsel bir değerlendirmesidir (Hart, 1999, s.566). Bu nedenle, yaşam doyumu genellikle bireyin genel yaşam kalitesini değerlendirmesinin global bir ölçüsü olarak görülmektedir (Lambert vd. 2009, s.690).

Literatürde yaş, cinsiyet, medeni durum, eğitim düzeyi ve gelir düzeyi gibi demografik değişkenlerin yaşam doyumu düzeyleri ile ilişkisine dair çalışmalar bulunmaktadır. Yaş, medeni durum, yükseköğrenim ve gelirin yüksek yaşam doyumuyla ilişkili olduğu saptanmıştır (Edwards ve Klemmacks, 1973, s.497; Linn, Yager, Cope ve Leake, 1986, s.2780; Iwatsubo, Derriennic, Cassou ve Poitrenaud, 1996, s.163; Lee vd. 2004, s.639). Öte yandan, literatürde cinsiyet farklılıkları ve yaşam doyumu ile ilgili araştırmalar yapılmıştır; ancak bulgular belirsizdir. Bazı araştırmalar kadınların erkeklerden daha yüksek yaşam doyumuna sahip olduğunu ortaya koyarken, bazı araştırmalar ise erkeklerin kadınlardan nispeten daha memnun olduklarını saptamıştır (Wood, Rhodes ve Whelan, 1989, s.249; Haring, Stock ve Okun, 1984, s.645; Brown ve Duan, 2007, s.268). Myers ve Diener (1995, s.16-17) sağlık, gelir düzeyi ve fiziksel çekiciliğin yaşam doyumu üzerindeki etkisinin küçük oranda olduğunu, bununla birlikte bireylerin adaptasyon kapasitesi, kültürel bakış açısı ve kişisel amaçlarının yaşam doyumuna daha büyük bir etkisinin olduğunu ifade etmektedirler. Para, sosyal beceriler ve zekâ eğer kişinin amaçları içerisinde yer alıyorsa yaşam doyumunu artırır (akt. Karakaplan Özer ve Doğan, 2017, s.308-309). Fernandez-Ballesteros, Zamarron ve Ruiz (2001, s.37) çalışmalarında, insanların yaşam doyumlarındaki değişikliğin sosyo-demografik koşullara bağlı olduğunu belirtmişlerdir. Bireylerin yaş, cinsiyet, medeni durum, eğitim ve gelir düzeylerinin, yaşam doyumunda farklılığa yol açabileceğine vurgu yapmışlardır. Genç, erkek, evli, eğitim ve gelir seviyesi yüksek bireylerin yaşlı bireylere göre yaşam doyumu seviyelerinin yüksek olduğu sonucuna da ulaşmışlardır. Melin, Fugl-Meyer ve Fugl-Meyer 
(2003, s.84) de çalışmalarında lojistik regresyon analizi kullanmışlar ve sonuç olarak iyi bir sağlık algısının, bir bütün olarak hayatın, yaşam alanlarının çoğunun memnuniyetinde en olumlu belirleyici olduğunu belirtmişlerdir. Ayrıca, eğitim seviyesinin memnuniyeti etkilediğini de vurgulamışlardır. Yorgun, Yılmaz ve Keser (2009, s.57) çalışmalarında, sendikalı otel işgörenlerinde demografik değişkenlerin iş doyumu ve yaşam doyumu üzerinde etkili olduğunu ortaya koymuşlardır. Karimi (2009, s.137) İranlı işgörenlerin iş ve yaşam doyumlarını incelediği çalışmasında, erkek işgörenlerin iş-aile etkileşimlerinin yaşamları veya işlerinde algıladıkları doyum üzerinde daha fazla etkiye sahipken, kadın işgörenler için ise çalışma saatleri ve aile-iş etkileşiminin iş veya yaşam doyumu üzerinde daha önemli bir etkiye sahip olduğu sonucuna ulaşmışlardır. Şad ve Şahin (2018, s.475) çalışmalarında, işgörenlerin eğitim düzeyinin artması ile yaşam doyumu düzeyinin arttığını, aylık gelir düzeyinin azaldığında yaşam doyumunun da azaldığını ve bölüm işgörenlerinin departman müdürlerine göre daha az yaşam doyumuna sahip oldukları sonucuna ulaşmışlardir.

\section{Yöntem}

Çalışmanın amacı, konaklama işletmelerinde çalışan işgörenlerin yaşam doyumu düzeylerinin belirlenmesi ve yaş, cinsiyet, eğitim, çalışma durumu, sektörde ve konaklama işletmesinde çalışma seneleri gibi demografik değişkenlerin işgörenlerin yaşam doyumuna olan etkilerinin saptanıp, analiz edilmesidir. Araştırmada kullanılan temel veri toplama aracı ankettir. Anketin ilk bölümünde işgörenlerin demografik özelliklerini belirlemeye yönelik sorulara yer verilmiştir. İkinci bölümde ise Diener vd. (1985) tarafından geliştirilen Yaşam Doyum Ölçeği kullanılmıştır. Yaşam doyumu ile ilgili sorular beşli Likert tipi ölçekle, demografik sorular ise kapalı uçlu olarak sunulmuştur.

Çalışma, Antalya'nın en çok turist çeken ilçelerinden biri olan Manavgat'ta yer alan konaklama işletmelerinde uygulanmıştır. Örneklem olarak Manavgat'ın tercih edilme sebebi, hem Türkiye'nin hem de Antalya'nın en çok turist çeken merkezlerinden biri olması yanında çalışmada daha 
verimli sonuçlar elde edilebilecek tüm yıl açık otellerin bulunmasıdır. Bölgede tüm yıl faaliyet gösteren 5 yıldızlı otellerden elde edilen 598 anket ile analizler değerlendirmeye alınmıştır.

İşgörenlerin vermiş oldukları cevaplar doğrultusunda elde edilen veriler SPSS 23.0 istatistik paket programı ile analiz edilmiştir. İstatistiksel anlamda öncelikle ölçeklerin güvenilirliği (Cronbach Alpha) test edilmiştir. Ardından değişkenlerin daha sağlıklı bir biçimde belirlenmesi amacıyla yaşam doyumu ölçeğine faktör analizi (principal component analysis) uygulanmıştır. İşgörenlerin demografik özelliklerinin yaşam doyumları üzerindeki etkilerini değerlendirmek için lojistik regresyon analizi kullanılmıştır.

\section{Bulgular}

Çalışmada, istatistiksel bazda verilere öncelikle güvenilirlik analizi uygulanmıştır ve yaşam doyumu ölçeğinin güvenilirlik değeri 0,879 olarak tespit edilmiştir. Yaşam doyumu ölçeğine ilişkin ayrıntılı sonuçlar Tablo 1'de yer almaktadır.

Tablo 1. Yaşam doyumu faktör analizi sonuçları

\begin{tabular}{|c|c|c|c|c|c|}
\hline & 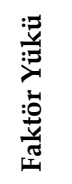 & 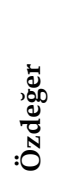 & 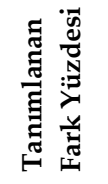 & 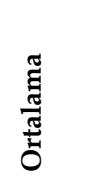 & 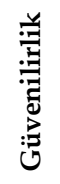 \\
\hline Yaşam Doyumu & & 3,436 & 68,727 & 3,4220 & 879 \\
\hline Yaşam koşullarım mükemmeldir & 890 & & & & \\
\hline Yaşamım beni tatmin ediyor & 876 & & & & \\
\hline $\begin{array}{l}\text { Şimdiye kadar, yaşamda istediğim önemli şeyleri } \\
\text { elde ettim }\end{array}$ & 846 & & & & \\
\hline Pek çok açıdan ideallerime yakın bir yaşamım var & 838 & & & & \\
\hline $\begin{array}{l}\text { Hayatımı bir daha yaşama şansım olsaydı, } \\
\text { hemen hemen hiçbir şeyi değiştirmezdim }\end{array}$ & 678 & & & & \\
\hline
\end{tabular}

Elde edilen bu güvenilirlik değerine göre, değişkenleri daha sağlıklı bir şekilde belirlemek ve ölçeğin yapı geçerliliğini sınamak amacıyla yaşam doyumu ölçeğine faktör analizi uygulanmıştır. Ölçek üzerinde gerçekleştirilen faktör analizinde, 5 sorunun Barlett küresellik testi sonuçları ile (,10 
ve Sig. $\mathrm{P}<0,001)$ Kaiser-Meyer-Olkin örneklem değerinin $(, 868)$ kabul edilebilir sınırlar içinde olduğu görülmüştür. Ölçeğe uygulanan temel bileşenler analizinde varimax faktör döndürme seçeneği kullanılmış ve elde edilen saçılma diyagramına göre özdeğerleri birin $(>1)$ üzerinde olan veriler değerlendirmeye alınmış ve tek boyut elde edilmiştir.

Çalışmaya ilişkin frekans analizleri ile ilgili detaylar Tablo 2'de yer almaktadır. Çalışmaya katılan işgörenlerin \%37,5'i kadın, \%62,5'i erkektir. İşgörenlerin \%58,9'u tam zamanlı, \%41,1'i sezonluk çalışmaktadır. İşgörenlerin, \%30,4'ü 17-25 yaş aralığında, \%42'si 26-35 yaş aralığında, \%21,4'ü $36-45$ yaş aralığında, \%5,5'i 46-55 yaş aralığında ve \%0,7'si ise 56 yaş ve üzerindedir. İşgörenlerin çalıştıkları bölümlerin dağılımına bakıldığında; ön büro çalışanları toplam çalışanların \%9'unu, F\&B (Food\&Beverage) çalışanları \%29,9'unu, kat hizmetleri çalışanları \%18,2'sini, muhasebe çalışanları \%9'unu ve diğer departmanlarda (teknik, animasyon, halkla ilişkiler) çalışanlar ise \%33,9'unu oluşturduğu görülmüştür. Aylık kazanç ile ilgili sonuçlara bakıldığında, işgörenlerin \%27,7'sinin 0-1604 TL arası, \%44,5'inin 1605-2000 TL aras1, \%21,1'inin 2001-3000 TL aras1, \%4,5'inin 3001-4000 TL arası ve $\% 2,2$ 'sinin 4001 TL ve üzeri gelire sahip olduğu görülmüştür. İşgörenlerin \%21,9'u ilköğretim, \%43,2'si lise, \%20,2'si ön lisans, $\% 12,9^{\prime}$ u lisans ve $\% 1,8^{\prime} i$ lisansüstü mezunudur.

Tablo 2. Örneklem profilinin sayısal ve yüzdesel dă̆ılım sonuçları

\begin{tabular}{|c|c|c|c|c|c|c|c|}
\hline & & Frekans & Yüzde & & & Frekans & Yüzde \\
\hline \multirow{4}{*}{$\begin{array}{l}\text { Cin- } \\
\text { siyet }\end{array}$} & Kadın & 224 & 37,5 & \multirow{3}{*}{$\begin{array}{l}\text { Çalışma } \\
\text { Durumu }\end{array}$} & Tam Zamanlı & 352 & 58,9 \\
\hline & Erkek & 374 & 62,5 & & Sezonluk & 246 & 41,1 \\
\hline & Toplam & 598 & 100 & & Toplam & 598 & 100 \\
\hline & & Frekans & Yüzde & & & Frekans & Yüzde \\
\hline \multirow{7}{*}{ Yaş } & $17-25$ & 182 & 30,4 & \multirow{6}{*}{$\begin{array}{l}\text { Depart- } \\
\text { man }\end{array}$} & Önbüro & 54 & 9,0 \\
\hline & $26-35$ & 251 & 42,0 & & $\mathrm{~F} \& \mathrm{~B}$ & 179 & 29,9 \\
\hline & $36-45$ & 128 & 21,4 & & Kat Hizmetleri & 108 & 18,2 \\
\hline & $46-55$ & 33 & 5,5 & & Muhasebe & 54 & 9,0 \\
\hline & 56 ve üzeri & 4 & 0,7 & & Diğer & 203 & 33,9 \\
\hline & Toplam & 598 & 100 & & Toplam & 598 & 100 \\
\hline & & Frekans & Yüzde & & & Frekans & Yüzde \\
\hline \multirow{7}{*}{$\begin{array}{l}\text { Ay- } \\
\text { lık } \\
\text { Ka- } \\
\text { zanç } \\
\text { (TL) }\end{array}$} & $0-1604$ & 166 & 27,7 & \multirow{7}{*}{ Eğitim } & İlköğretim & 131 & 21,9 \\
\hline & $1605-2000$ & 266 & 44,5 & & Lise & 258 & 43,2 \\
\hline & $2001-3000$ & 126 & 21,1 & & Ön lisans & 121 & 20,2 \\
\hline & $3001-4000$ & 27 & 4,5 & & Lisans & 77 & 12,9 \\
\hline & 4001ve üzeri & 13 & 2,2 & & Lisansüstü & 11 & 1,8 \\
\hline & Toplam & 598 & 100 & & & & \\
\hline & & & & & Toplam & 598 & 100 \\
\hline
\end{tabular}


Çalışmanın odak noktasını oluşturan lojistik regresyon analizi yine SPSS paket programı yardımıyla gerçekleştirilmiş, analize dahil edilen örneklem sayısı özet olarak Tablo 3 'te verilmiş ve aşağıdaki sonuçlar elde edilmiştir. Açıklanan (bağımlı) değişkenin nasıl kodlandığı yani yaşam doyumu düzeyinin düşük ya da yüksek olduğu "Bağımlı Değişken Kodlaması" tablosunda gösterilmektedir (Tablo 4). Kodlama; 0=düşük, 1=yüksek olarak gerçekleştirilmiştir. "Kategorik Değişken Kodlaması" tablosunda, kategorik değişkenlerin frekans ve kodlamaları görülmektedir (Tablo 5). "Çalışma durumu" değişkeninde 1=Tam Zamanlı, 0=Sezonluk olarak kodlanmıştır. "Yaş" değişkeninde 35 yaş ve altı 415 kişi, 36 yaş ve üzeri 183 kişi bulunmaktadır ve $1=35$ ve altı, $0=36$ ve üstü olarak kodlanmiştır.

Tablo 3. Veri özet bulguları

\begin{tabular}{llll}
\hline Vakalar & & Frekans & Yüzde \\
\hline \multirow{3}{*}{ Seçilmiş Vakalar } & Analize Dahil Edilenler & 598 & 100,0 \\
\cline { 2 - 4 } & Kayıp Veri & 0 &, 0 \\
\cline { 2 - 4 } & Toplam & 598 & 100,0 \\
\hline Seçilmemiş Vakalar & & 0 &, 0 \\
\hline Toplam & & 598 & 100,0 \\
\hline
\end{tabular}

Tablo 4. Bă̆ımlı değişken kodlaması

\begin{tabular}{ll}
\hline Orijinal Değer & Dahili Değer \\
\hline Düşük & 0 \\
\hline Yüksek & 1 \\
\hline
\end{tabular}

Tablo 5. Kategorik değişken kodlaması

\begin{tabular}{llll}
\hline & & Frekans & Parametre Kodları \\
\hline \multirow{2}{*}{ Çalışma durumu } & Tam zamanlı & 352 & 1,000 \\
\hline \multirow{2}{*}{ Yaş } & Sezonluk & 246 & 0,000 \\
\hline \multirow{2}{*}{ Cinsiyet } & 35 ve altı & 415 & 1,000 \\
\cline { 2 - 4 } & 36 ve üstü & 183 & 0,000 \\
\hline & Erkek & 374 & 1,000 \\
\hline
\end{tabular}


"Cinsiyet" değişkeni incelendiğinde, 374 erkek ve 224 kadın işgören olduğu görülmektedir ve $1=$ erkek, $0=$ kadın olarak kodlanmıştır. Diğer demografik değişkenlerle ilgili kodlamalar ise şu şekilde yapılmıştır: Kazanç; 1=0-1604 TL, 2=1605 TL-2000 TL, 3=2001 TL-3000 TL, 4=3001 TL-4000 $\mathrm{TL}, 5=4001 \mathrm{TL}$ ve üzeri olarak kodlanmıştır. Eğitim; 1=Illköğretim, 2=Lise, 3=Ön lisans, 4=Lisans, 5=Lisansüstü olarak kodlanmıştır.

"Sınıflandırma Tablosu" bağımlı değişkenin her bir kategorisi için vaka sayılarını göstermektedir (Tablo 6). Satırlarda gözlenen, sütunlarda ise sınıflandırma bilgileri yer almaktadır. Çalışmada, işgörenler yaşam doyumu yüksek kategorisinde sınıflandırılmıştır. Bağımsız değişkenler hakkında hiçbir şey bilinmediğinde, işgörenlerin yaşam doyumlarının yüksek olduğu (yaşam doyumu yüksek olanlar (477) düşük olanlardan (121) daha fazla) şeklindeki tahminin en iyi tahmin olacağı ve bu haliyle doğru sınıflandırma yüzdesinin $\% 79,8$ olacağı ortaya çıkmıştır.

Tablo 6. Sinıflandırma tablosu

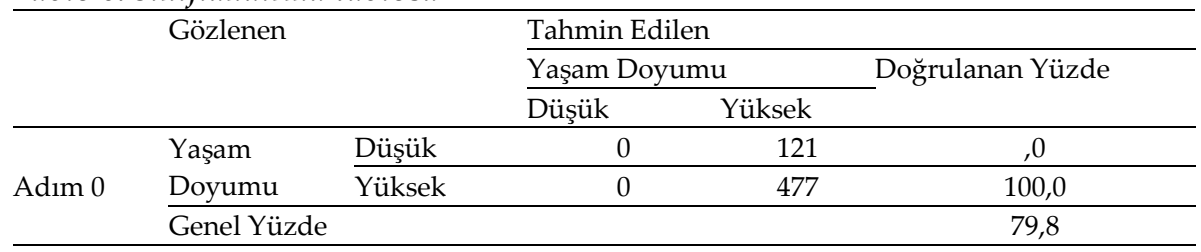

"Denklemdeki Değişkenler" tablosuna bakıldığında (Tablo 7), odds ratio değeri olan $\operatorname{Exp}(B)$ 'nin 3,942 olarak bulunduğu ve Wald istatistik değerine $(p<0,001)$ göre de anlamlı olduğu tespit edilmiştir. Bu değer, analize tabi tutulan işgörenlerden herhangi birinin yaşam doyumunun yüksek çıkma olasılığı, düşük çıkmasına göre 3,942 kat daha fazla olacağını göstermektedir.

Tablo 7. Denklemdeki değişkenler

\begin{tabular}{|c|c|c|c|c|c|c|c|}
\hline & & B & S.E. & Wald & Df & Sig. & $\operatorname{Exp}(B)$ \\
\hline Adım 0 & Sabit Değer & 1,372 & 102 & 181,609 & 1 & ,000 & 3,942 \\
\hline
\end{tabular}

"Hosmer ve Lemeshow Testleri İçin Olasılık Durum Tablosu”nda (Tablo 8), bağımlı değişkene göre verinin 10 gruba ayrıldığı görülmektedir. Gözlenen ve beklenen değerlerin oldukça birbirine yakın değerler olması arzu edilen bir sonuçtur (Gürbüz ve Şahin, 2017, s.306). Başka bir 
ifadeyle grup üyelikleri hakkında türetilen tahminler gerçek durumla oldukça yakındır, bu da model uyumunun bir göstergesidir.

Tablo 8. Hosmer ve Lemeshow testleri için olasılık durum tablosu

\begin{tabular}{|c|c|c|c|c|c|c|}
\hline \multirow[t]{2}{*}{ 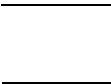 } & & \multicolumn{2}{|c|}{ Düşük $=0,00$} & \multicolumn{2}{|c|}{ Yüksek $=1,00$} & \multirow[t]{2}{*}{ Toplam } \\
\hline & & Gözlenen & Beklenen & Gözlenen & Beklenen & \\
\hline \multirow{10}{*}{ Adım 1} & 1 & 20 & 17,106 & 40 & 42,894 & 60 \\
\hline & 2 & 16 & 15,282 & 44 & 44,718 & 60 \\
\hline & 3 & 10 & 14,080 & 50 & 45,920 & 60 \\
\hline & 4 & 12 & 13,181 & 48 & 46,819 & 60 \\
\hline & 5 & 11 & 12,438 & 50 & 48,562 & 61 \\
\hline & 6 & 13 & 11,500 & 47 & 48,500 & 60 \\
\hline & 7 & 8 & 10,371 & 50 & 47,629 & 58 \\
\hline & 8 & 11 & 9,977 & 49 & 50,023 & 60 \\
\hline & 9 & 11 & 9,126 & 49 & 50,874 & 60 \\
\hline & 10 & 9 & 7,939 & 50 & 51,061 & 59 \\
\hline
\end{tabular}

"Katsayı Tahminleri" tablosu, bağımsız değişkenler ve sabit katsayı ile ilgili B değerlerini göstermektedir (Tablo 9). Söz konusu B’ler, çoklu regresyonda tahmin fonksiyonu oluşturulmasında kullanılırken lojistik regresyonda kişinin bir işi ya da diğerini yapma ihtimalini belirlemede kullanılır (Özkan, 2013, s.47). Exp (B), bağımlı değişkenin bağımsız değişkenin etkisi ile kaç kat daha fazla (veya az) ya da \% kaç oranında fazla gözlenme olasılığına sahip olduğunu gösterir. Exp (B) sütunu her bir bağımsız değişken ile ilişkili olarak olasılık oranını göstermektedir; ayrıca \%95 güven aralığında en düşük ve en yüksek değerler de analiz sonucunda yer almaktadır (Gürbüz ve Şahin, 2017, s.307). Modele ait Exp (B) değerleri incelendiğinde, yaşam doyumunun sırasıyla; eğitim durumu arttıkça 1,140 kat, kazanç durumu arttıkça 1,125 kat, sektörde çalışma süresi arttıkça 1,011 kat artacağ görülmekle birlikte, işletmede çalışma süresi arttıkça 0,983 kat azalacağ gruba göre 0,961 kat, erkeklerin kadınlara göre 0,851 kat, tam zamanlı çalişanların sezonluk çalışanlara göre 0,627 kat daha az yaşam doyumuna sahip olacağı belirlenmiştir. Denklemde belirlenen Exp (B) değerlerinin istatistiksel anlamlılığına bakıldığında ise sadece çalışma durumu bağımsız değişkeninin ( $\mathrm{p}=0,047), 0,05$ anlamlılık seviyesinde istatistiksel olarak anlamlı olduğu saptanmıştır. Bu sonuç, çalışma durumunda meydana gele- 
bilecek değişimin (tam zamanlı çalışmanın sezonluk çalışmaya göre) yaşam doyumunu 0,627 kat azaltacağını ve bu azalmanın da anlamlı olduğunu göstermektedir.

Tablo 9. Katsayı tahminleri

\begin{tabular}{llllllll}
\hline & & B & S.E. & Wald & Df & Sig. & Exp(B) \\
\hline \multirow{4}{*}{ Adım 1a } & & & & & & \\
\cline { 2 - 7 } & Cinsiyet(1) &,- 162 &, 217 &, 554 & 1 &, 457 &, 851 \\
\cline { 2 - 7 } & Yaş(1) &,- 040 &, 266 &, 022 & 1 &, 882 &, 961 \\
\cline { 2 - 4 } &, 118 &, 131 &, 810 & 1 &, 368 & 1,125 \\
\cline { 2 - 7 } & Eğitim &, 131 &, 116 & 1,264 & 1 &, 261 & 1,140 \\
\cline { 2 - 7 } & İletmede Çalışma &,- 018 &, 038 &, 214 & 1 &, 644 &, 983 \\
\cline { 2 - 7 } & Sektörde Çalışma &, 011 &, 022 &, 255 & 1 &, 614 & 1,011 \\
\cline { 2 - 5 } &,- 467 &, 235 & 3,946 & 1 &, 047 &, 627 \\
\cline { 2 - 7 } & Sabit Değer & 1,223 &, 410 & 8,901 & 1 &, 003 & 3,398 \\
\hline
\end{tabular}

a. Adım 1'de girilen değişkenler: cinsiyet, kazanç, eğitim, çalışma durumu, sektörde çalışma, işletmede çalışma, yaş.

\section{Sonuç ve tartışma}

Bu çalışmada, cinsiyet, yaş, eğitim durumu, işletmede çalışma süresi, sektörde çalışma süresi ve çalışma durumu gibi demografik değişkenlerin konaklama işletmeleri işgörenlerinin yaşam doyumları üzerindeki etkilerinin belirlenmesi amaçlanmıştır. İşgörenlerin yaşam doyumu düzeyinin 3,42 ortalama ile orta düzeylerde bir değere sahip olduğu görülmüştür. Çalışmanın amacı doğrultusunda, işgörenlerin yaşam doyumu üzerinde etkili olan demografik faktörlerin belirlenmesi için lojistik regresyon analizi kullanılmıştır. Bu analiz sonucunda, sadece çalışma durumu $(p=0,047)$ bağımsız değişkeninin istatistiksel olarak anlamlı olduğu saptanmıştır. Burada çalışma durumunda meydana gelebilecek değişimin (tam zamanlı çalışmanın sezonluk çalışmaya göre) yaşam doyumunu 0,627 kat azaltacağı görülmüştür.

Bununla birlikte, çalışmada yaşam doyumu üzerindeki etkilerinin incelendiği "eğitim durumu, kazanç, sektörde çalışma süresi, işletmede çalışma süresi, yaş ve cinsiyet" değişkenleri ise istatistiksel olarak anlamlı sonuçlar vermemiştir. Haring vd. (1984, s.645) ve Brown ve Duan (2007, s.267) çalışmalarında benzer şekilde, cinsiyetin yaşam doyumunu etkileyen ana belirleyici olmadığı sonucunu elde etmişlerdir. Lee vd. (2004, s.63) 
ve Iwatsubo vd. (1996, s.166) de çalışmalarında yaşın, yaşam doyumu düzeyini etkilemediği sonucuna ulaşmışlardır. Saldamlı (2008) da çalışmasında, kişisel ve demografik faktörlerin yaşam doyumu üzerinde etkisi konusunda bir genelleme yapılamayacağını belirtmiştir. Yaş, cinsiyet, eğitim durumu gibi demografik özelliklerin bireyin yaşam doyumu üzerinde tek başına etkisinin olamayacağını vurgulamıştır. Öte yandan, Şad ve Şahin (2018, s.475) ise araştırmalarında, işgörenlerin eğitim düzeyinin artması ile yaşam doyumu düzeyinin arttığını, aylık gelir düzeyinin azaldığında yaşam doyumunun da azaldığını ve bölüm işgörenlerinin bölüm müdürlerine göre daha düşük yaşam doyumuna sahip oldukları sonucuna ulaşmışlardır. Bununla birlikte, faktörlerin bir şekilde yaşam doyumu üzerinde etkili olduğu kabul edilse bile, bireyin içinde bulunduğu sosyo-kültürel çevre, iş, inanç ve değerlerin yaşam doyumu üzerindeki etkisinin göz ardı edilmemesi gerekir (Saldamlı, 2008, s.701).

Yapılan literatür incelemesinde, turizm işletmeleri işgörenleri ile gerçekleştirilmiş bu tür bir çalışmaya rastlanmamıştır. Bu çerçevede, çalışmanın literatüre katkı sağlayan özgün bir çalışma olduğu söylenebilir. Bununla birlikte, Manavgat otelleriyle sinırlı tutulan bu çalışma bundan sonra gerçekleştirilecek çalışmalarla geliştirilebilir. Diğer bölgeler de araştırmaya dahil edilerek araştırmanın kapsamı genişletilebilir. Konaklama işletmelerinde, sektör, örgüt ve işgörenler için verimliliği artıracak önemli unsurlardan biri olan yaşam doyumunun farklı demografik değişkenlere göre düşük ya da yüksek çıkması, işletmelerin alacağı önlemlerle işgörenlerin lehine çevrilebilirse, bu olumlu değişimin işletmeler için de olumlu sonuçlar sağlayabileceği göz önünde bulundurulmalıdır. 
EXTENDED ABSTRACT

\title{
Determination of the Effects of Demographic Variables on Life Satisfaction by Logistics Regression Analysis: Case of the Accommodation Sector
}

\author{
Boran Toker - M. Bahadır Kalıpçı \\ * \\ Akdeniz University
}

It can be said that life satisfaction in accommodation businesses in the service sector is one of the important factors both employee and business for increasing performance and efficiency. Today, contemporary managers should not only focus on service quality. It is a fact that it is possible to increase work efficiency and loyalty of employees by increasing the life satisfaction of employees. Life satisfaction is the degree to which a person positively evaluates the overall quality of his/her life as-a-whole. In other words, how much the person likes the life he/she leads (Veenhoven, 1996, p. 6). Various studies have shown that how life satisfaction will change with the effect of different demographic variables. The aim of this study is to determine the level of life satisfaction of the employees and the effects of demographic variables such as age, gender, education, working status, working years in sector and working years in accommodation business on life satisfaction.

The concept of life satisfaction is generally examined as a component under the basic structures such as subjective well-being (SWB) in the literature. At the cognitive level, SWB includes a global sense of satisfaction with life, fed by specific satisfactions with one's work, marriage, and other domains. At the affective level, people with high SWB feel primarily pleasant emotions, thanks largely to their positive appraisal of ongoing events. People with low SWB appraise their life circumstances and events as undesirable, and therefore feel unpleasant emotions such as anxiety, depression, and anger (Myers and Diener, 1995, p.11). 
Life Satisfaction includes the desire to change life, satisfaction with current life, satisfaction with past, satisfaction with future, and others' views about one's life. Satisfaction domains include work, family, leisure, health, finance, personality, and one's close group (Diener et al., 1999, p.277). Life satisfaction generally includes the whole life of the individual and the different dimensions of this life (Toker and Çelik, 2016, p.337). In this context, life satisfaction is defined as the degree to which the experience of an individual's life satisfies his/her personal wants and needs (both physical and psychological) (Rice, 1984, p.3). These wants and needs may exist in several domains of life, for example when individuals take the role of employee, parent, spouse or friend (Demerouti et al., 2000, p.456).

\section{Method}

Survey is the main data collection technique used in the study. The data were obtained by using Diener et al.'s (1985) Life Satisfaction Scale and personal information form. The study was carried out in the accommodation businesses located in Manavgat, one of the most popular tourism destination of Antalya. 598 usable questionnaires were obtained from 5-star hotels operating all year in Manavgat. Research data were analyzed with SPSS 23.0 statistical package program. Firstly, the reliability of the scales (Cronbach Alpha) was tested. Next, factor analysis (principal component analysis) was applied to the life satisfaction scale in order to determine the variables more accurately. Logistic regression analysis was used to determine the effects of independent variables consisting of categorical variables on the binary dependent variable.

\section{Results}

In the study, reliability analysis was applied to the data and Cronbach's alpha value of the life satisfaction scale was determined was 0.879 . In the factor analysis performed on the life satisfaction scale, one dimension was obtained from 5 questions. On the other hand, some of the frequency analysis of this study are as follows. $37.5 \%$ of employees are female and $62.5 \%$ were male. $58.9 \%$ of employees are full-time while remaining $41.1 \%$ as seasonal. $42 \%$ of employees are aged between $26-35$, while approximately 
$43 \%$ are high school graduates. Logistic regression analysis was used to evaluate the effects of demographic characteristics of the employees on life satisfaction. When the Exp (B) values of the model are examined, life satisfaction increases as education level increases by 1.140 times, as income level increases by 1.125 times, as the working years in sector increases by 1.011 times. However, life satisfaction decreases 0.983 times as the working years in accommodation business increases. Moreover, it is determined that the people at the age of 35 years and below have 0.961 times lower life satisfaction compared to 36 years old and over, men 0.851 times lower compared to women, and full time workers 0.627 times lower compared to seasonal workers. When the statistical significance of the Exp (B) values determined in the equation was examined, it was found that only working status independent variable $(\mathrm{p}=0.047)$ was statistically significant at the 0.05 significance level. This result shows that the change in working status (full time work according to seasonal work) will decrease the life satisfaction by 0.627 times and this decrease is also statistically significant.

\section{Conclusion}

In this study, it was aimed to determine the effects of demographic variables such as gender, age, education level, working years in business, working years in sector and working status on life satisfaction of accommodation businesses employees. The level of life satisfaction of the employees was found to have a moderate level with an average of 3.42. For the purpose of the study, logistic regression analysis was used to determine the demographic factors affecting the life satisfaction of the employees. As a result of this analysis, it was found that only the working status ( $\mathrm{p}=0.047)$ was statistically significant. In this context, it was found that the change in working status (full-time work according to seasonal work) would decrease life satisfaction by 0.627 times. However, in the study, it was concluded that there was no statistically significant effect of education, income, working status, working years in sector and accommodation business, age, and sex variables on life satisfaction.

Life satisfaction is one of the important factors that will increase productivity in accommodation businesses. If the effects of demographic 
variables on life satisfaction can be converted in favor of the employees with the measures to be taken by the businesses, positive results can be obtained for the businesses.

\section{Kaynakça / References}

Brown, C. ve Duan, C. (2007). Counselling psychologists in academia: life satisfaction and work and family role commitments. Counselling Psychology Quarterly, 20(3), 267-285.

Demerouti, E., Bakker, A.B., Nachreiner, F. ve Schaufeli, W.B. (2000). A model of burnout and life satisfaction amongst nurses. Journal of Advanced Nursing, 32(2), 454-464.

Diener, E., Emmons, R.A., Larsen, R.J. ve Griffin, S. (1985). The satisfaction with life scale. Journal of Personality Assessment, 49(1), 71-75.

Diener,E., Suh, E.M., Lucas, R.E. ve Smith, H. L. (1999). Subjective wellbeing: three decades of progress. Psychological Bulletin, 125(2), 276302.

Donovan, N. ve Halpern, D. (2002). Life satisfaction: the state of knowledge and implications for government. United Kingdom: Cabinet Office Strategy Unit.

Edwards, J.N. ve Klemmacks, D.L. (1973). Correlates of life satisfaction: a re-examination. Journal of Gerontology, 28(4), 499-502.

Fernandez-Ballesteros, R., Zamarron, M. D. ve Ruiz, M. A. (2001). The contribution of socio-demographic and psychosocial factors to life satisfaction. Ageing and Society, 21(1), 25-43.

Gürbüz, S. ve Şahin, F. (2017). Sosyal bilimlerde araştırma yöntemleri felsefeyöntem-analiz, Ankara: Seçkin Akademik ve Mesleki Yayınlar.

Hart, P. (1999). Predicting employee life satisfaction: a coherent model of personality, work and nonwork experiences, and domain satisfactions. Journal of Applied Psychology, 84(4), 564-584.

Haring, M.J., Stock, W.A. ve Okun, M.A. (1984). A research synthesis of gender and social class as correlates of subjective wellbeing. $\mathrm{Hu}$ man Relations, 37(8), 645-657.

Iwatsubo, Y., Derriennic, F., Cassou, B. ve Poitrenaud, J. (1996). Predictors of life satisfaction amongst retired people in Paris. International Journal of Epidemiology, 25(1), 160-170. 
Joshanloo, M. ve Afshari, S. (2011). Big five personality traits and self-esteem as predictor of life satisfaction in Iranian muslim university students. Journal of Happiness Studies, 12(1), 105-113.

Karakaplan-Özer, E. ve Doğan, E. (2017). Yaşam doyumu ve performans ilişkisi: adıyaman üniversitesi akademik personeli uygulaması. International Journal of Academic Value Studies, 3(2), 307-315.

Karimi, L. (2009). Do female and male employees in Iran experience similar work-family interference, job and life satisfaction?. Journal of Family Issues, 30(1), 124-142.

Lambert, E.G., Hogan, N.L., Elechi, O.O., Jiang, S., Laux, J.M., Dupuy, P. ve Morris, A. (2009). A further examination of antecedents of correctional staff life satisfaction. The Social Science Journal, 46, 689706.

Lee, H., Hwang, S., Kim, J. ve Daly, B. (2004). Predictors of life satisfaction of Korean nurses. Journal of Advanced Nursing, 48(6), 632-641.

Lewis, V. ve Borders, L. (1995). Life satisfaction of single middle-aged professional women. Journal of Counseling and Development, 74(1), 94100.

Linn, L.S., Yager, J., Cope, D. ve Leake B. (1985). Health status, job satisfaction, job stress, and life satisfaction among academic and clinical faculty. JAMA The Journal of the American Medical Association, 254(19), 2775-2782.

Medley M.L. (1976). Satisfaction with life among person sixty-five years and olders. Journal of Gerontology, 31(4), 448-455.

Melin, R., Fugl-Meyer, K. S. ve Fugl-Meyer, A. T. (2003). Life satisfaction in 18 to 64 year old swedes: in relation to education, employment situation, health and physical activity. J Rehabil Med, 35(2), 84-90.

Myers, D. G. ve Diener, E. (1995). Who is happy?. Pyschological Science, 6(10), 10-19.

Özkan, M. (2013). Lojistik regresyon analizi ile öğretmenler üzerinde bir uygulama. Ordu Üniversitesi Sosyal Bilimler Araştırmaları Dergisi, 4(7), 43-48.

Pasupuleti, S., Allen, R.I., Lambert, E.G. ve Cluse-Tolar, T. (2009). The impact of work stressors on the life satisfaction of social service workers: A preliminary study. Administration in Social Work, 33(3), 319339. 
Rice, R.W. (1984). Organizational work and the overall quality of life. Applied Social Psychology Annual, 5, 155-178.

Saldamlı, A. (2008). Otel işletmelerinde bölüm yöneticilerinin iş ve yaşam tatminini belirlemeye yönelik bir alan araştırması. Marmara Üniversitesi İ.I.B.F. Dergisi, 25(2), 693-719.

Şad, B. ve Şahin, S. (2018). Otel çalışanlarının tükenmişlik düzeyinin yaşam doyumuna etkisi. Seyahat ve Otel İşletmeciliği Dergisi, 15(2), 461-480.

Toker, B. ve Çelik, S. (2016). Örgütsel bağlılık iş tatmini yaşam tatmini ile işten ayrılma niyeti arasındaki ilişkiler: konaklama sektöründe bir uygulama. 24. Ulusal Yönetim ve Organizasyon Kongresi: Bildiriler Kitabı, içinde (s.335-343). İstanbul: Sabancı Üniversitesi.

Veenhoven, R. (1996). The study of life satisfaction. (W.E. Saris, R. Veenhoven, A.C. Scherpenzeel, B. Bunting, Der.), A comparative study of satisfaction with life in Europe, içinde (s. 11-48). Budapest:Eötvös University Press.

Wood, W., Rhodes, N. ve Whelan, M. (1989). Sex differences in positive well-being: a consideration of emotional style and marital status. Psychological Bulletin, 106(2), 249-264.

Yetim, U. (1991). Kişisel projelerin organizasyon ve örüntüsü açısından yaşam doyumu. Yayınlanmamış doktora tezi, Ege Üniversitesi, İzmir.

Yorgun, S., Yılmaz, G. ve Keser, A. (2009) The relationships of job and life satisfaction with intention to leave among unionized hotel employees in Turkey. İş, Güç Endüstri İlişkileri ve İnsan Kaynakları Dergisi, 11(2), 55-67.

\section{Kaynakça Bilgisi / Citation Information}

Toker B. ve Kalıpçı, M. B. (2019). Demografik değişkenlerin yaşam doyumuna etkisinin lojistik regresyon analizi ile belirlenmesi: Konaklama sektörü örneği. OPUS-Uluslararası Toplum Araştırmaları Dergisi, 12(18. UİK Özel Sayıs1), 544-562. DOI: 10.26466/opus.589382. 